\title{
Emerging non-invasive detection methodologies for lung cancer (Review)
}

\author{
ZHEN LI ${ }^{1,2}$, JINIAN SHU ${ }^{2}$, BO YANG ${ }^{2}$, ZUOJIAN ZHANG $^{2}$, JINGYUN HUANG $^{2}$ and YANG CHEN ${ }^{1}$ \\ ${ }^{1}$ Beijing Advanced Sciences and Innovation Center, Chinese Academy of Sciences, Beijing 101407; \\ ${ }^{2}$ National Engineering Laboratory for VOCs Pollution Control Material and Technology, \\ University of Chinese Academy of Sciences, Beijing 101408, P.R. China
}

Received July 6, 2019; Accepted January 17, 2020

DOI: $10.3892 / \mathrm{ol} .2020 .11460$

\begin{abstract}
The potential for non-invasive lung cancer (LC) diagnosis based on molecular, cellular and volatile biomarkers has been attracting increasing attention, with the development of advanced techniques and methodologies. It is standard practice to tailor the treatments of LC for certain specific genetic alterations, including the epidermal growth factor receptor, anaplastic lymphoma kinase and $B R A F$ genes. Despite these advances, little is known about the internal mechanisms of different types of biomarkers and the involvement of their related biochemical pathways during the development of LC. The development of faster and more effective techniques is essential for the identification of different biomarkers. The present review summarizes some of the latest methods used for detecting molecular, cellular and volatile biomarkers in LC and their potential use in clinical diagnosis and targeted therapy.
\end{abstract}

\section{Contents}

1. Introduction

2. Emerging non-invasive detection technologies for lung cancer

3. Challenges and future directions

\section{Introduction}

In 2018, lung cancer (LC) was reported as the leading cause of cancer-associated mortality worldwide (1), early screening of LC is regarded as a significant means to improve patient survival. Over the past 20 years, various mechanisms of LC and their detection methods have been comprehensively studied

Correspondence to: Dr Zhen Li, Beijing Advanced Sciences and Innovation Center, Chinese Academy of Sciences, 26 South Yanqi Street, Huairou Science City, Huairou, Beijing 101407, P.R. China E-mail: lizhen@basic.cas.cn

Key words: lung cancer, non-invasive, detection in liquid biopsy samples (2). A number of clinical molecular diagnostic tests for LC have been developed based on these studies (3-5). The objectives of these diagnostic methods include early detection, screening for therapeutic targets, profiling cancer panel, monitoring therapeutic effectiveness and early recurrence detection. At the genetic level, the most relevant genes that are assessed for LC include epidermal growth factor receptor $(E G F R), K R A S$ and anaplastic lymphoma kinase $(A L K)(6)$. At the protein level, a number of antigen detection methods, including carcinoembryonic antigen (CEA), cancer antigen 125 and cytokeratin fragment 21-1, have also been studied to improve diagnostic accuracy (7). At the cellular level, the examination of circulating tumor cells (CTCs) has been shown to provide prognostic information concerning tumor metastasis (8). Moreover, exhaled volatile organic compounds (VOCs) are considered to be optimal non-invasive biomarkers since they are indicative of the mutations and pathophysiological processes of LC (9).

Recent advances in the field of VOC biomarkers have improved the sensitivity and specificity in the diagnosis of LC (10). A VOC pattern or specific VOCs can be detected and used as a potential guide for the development of effective therapeutics (11). The use of mass spectrometers or sensors for the precise detection of volatile biomarkers could substantially aid the diagnostic process by supplementing the standard screening methods in the early diagnosis and prognosis of patients with LC.

In the current review, the related mechanisms of molecular, cellular and volatile biomarkers for LC and techniques used for their detection are discussed. In addition, the detection characteristics of the different diagnostic methods are compared. Important improvements are required in certain areas, including the following: i) Exploring the relationship between liquid biopsies and volatile biomarkers in standardized clinical trials of LC; ii) customizing the anticancer strategies; and iii) developing more sensitive and selective instruments for biomarker detection.

\section{Emerging non-invasive detection methods for LC}

Methods of interest. Evaluation of the intratumor heterogeneity of patients used to be based on surgical resection sampling and multiple biopsies. However, recent advances in sampling 
are focused on acquiring sufficient samples for various biomarkers using minimally invasive or non-invasive methods, including liquid biopsy for the detection of circulating tumor (ct)DNA. (12), circulating tumor cells (CTCs) (13) and protein biomarkers (14), and analysis of exhaled VOCs (15). The specific characteristics that were compared between these less invasive (nucleic acid, protein and cell based) and non-invasive (VOCs based) detection methods for the diagnosis of LC are listed in Table I.

Nucleic acid-based detection. i) ctDNA markers. Liquid biopsy is thought to be one of the potential options for the non-invasive diagnosis of LC. ctDNA is secreted into the serum by necrotic or apoptotic cells, which may provide effective means for tumor diagnoses (16). Additionally, the short half-life of ctDNA $(\sim 2 \mathrm{~h})$ renders it an ideal dynamic marker of tumors (17). Some genetic mutations, particularly single nucleotide variants (SNVs) in ctDNA may be considered as specific biomarkers for LC. A study assessing 100 early-stage non-small cell lung cancer (NSCLC) specimens revealed that $48 \%$ of patients had $\geq 2$ detectable SNVs in ctDNA. Post-operative next-generation sequencing (NGS) based on ctDNA analysis is able to predict LC recurrence earlier than CT imaging, at 70 days (18). Furthermore, Cohen et al (19) used CancerSEEK, a PCR-based ctDNA method, for the detection of five cancer types, namely ovarian, liver, stomach, pancreatic and esophageal cancer, and reported that the accuracy of prediction varied with tumor type. The performance of CancerSEEK in the analysis of 104 LC samples was poor, with only $59 \%$ sensitivity; even when combined with machine learning, the accuracy was lowest for LC.

Although ctDNA analysis for LC is promising, it remains incomplete. Disadvantages of this method, which hamper its widespread application, include the following: a) Poor detection sensitivity; b) high cost; and c) limited clinical utility. More specifically, the concentration of ctDNA in plasma is only $1 \%$, and as much as $10 \mathrm{ml}$ plasma are required to obtain reliable results when using the current ctDNA platforms. Regarding the cost of liquid biopsy testing, this has been estimated at US\$1,750 per patient. Moreover, ctDNA analysis is technically complex and requires specialized skills and equipment (18).

ii) Methylated DNA markers. Aberrant hypermethylation of global DNA or specific $\mathrm{CpG}$ islands in promoter regions has been considered a promising biomarker for different cancer types, including ovarian, prostate, liver and cervical cancer (20). Methylated DNA markers in LC have been detected in various body fluid samples, including blood, serum, pleural effusion and ascites (21). Improvements of this detection method currently enable the determination of DNA methylation. Wielscher et al (22) reported a panel of four methylated genes, specifically homeobox D10, paired box 9, protein tyrosine phosphatase receptor type 2 and stromal antigen 3 , as markers for LC detection. LC was efficiently differentiated from other lung diseases and controls with a sensitivity of $87.8 \%$ and a specificity of $90.2 \%$. The commercial test kit Epi proLung $^{\circledR}$ (Epigenomics Inc.), used for the screening of LC and based on the analysis of methylation in the short stature homeobox 2 (SHOX2) gene, was approved by the Chinese Food and Drug Administration (FDA) in July 2015 (23). To estimate the diagnostic efficacy of SHOX2 DNA methylation, a meta-analysis was conducted in 2,296 subjects, including 1,129 patients with $\mathrm{LC}$, which demonstrated that this method had $70 \%$ sensitivity and $96 \%$ specificity (24).

Three groups of methods are commonly employed to distinguish methylated DNA from unmethylated DNA, including sodium bisulfite conversion, restriction enzyme and specific antibodies (25). DNA methylation may be analyzed using various detection methods, including PCR, microarrays, and NGS. However, each of these methods has certain drawbacks; bisulfite conversion results in random DNA fragmentation (26). In addition, restriction enzyme-based methods can only detect specific patterns of $\mathrm{CpG}$ sites. Antibody-based methods are limited by a low recovery rate (27). Moreover, the establishment of standardized protocols for methylation detection methods is essential.

iii) MicroRNA (miRNA/miR) markers. miRNAs are small non-coding RNAs that are capable of influencing cancer metabolism by regulating tumor suppressor signaling pathways of glucose metabolism or the expression of glycolytic enzymes (28). The miRNA expression profiles for LC have been found to be present and stably expressed in bodily fluids, including human serum/plasma and sputum (29). For instance, findings have demonstrated a significantly decreased expression of miRNA-124-5p and an increased expression of miRNA-124-2 and miRNA-124-3 in patients with advanced-stage LC $(30,31)$. Moreover, miRNA expression patterns may serve as specific biomarker signatures for the diagnosis and subtype differentiation of LC from early stage to metastatic $(32,33)$. In a cohort of 180 subjects (92 patients; 88 healthy participants), a plasma miRNA signature, consisting of miRs-126, -145, -210 and -205-5p, was defined by NGS and shown to have $91.5 \%$ sensitivity and $96.2 \%$ specificity in the detection of LC (34). In another study, a panel of six miRNAs, namely miR-17, miR-190b, miR-19a, miR-19b, miR-26b and miR-375, was used for the diagnosis and further differentiation of small cell lung cancer from NSCLC in 1,132 participants by microarray analysis and was found to have $80 \%$ sensitivity and $80 \%$ specificity (33).

In addition, numerous plasma miRNAs have been identified using microarray platforms and are considered as plasma biomarkers for LC $(35,36)$. These miRNAs are usually further verified by reverse transcription (RT)-quantitative PCR analysis. Nevertheless, microarray-based methods are limited by relatively low sensitivity and specificity. Therefore, they have yet to be applied in clinical settings. By contrast, NGS is able to identify LC-associated miRNAs with high throughput and high sensitivity and specificity (37).

In combination with certain algorithms, miRNA analyses may have powerful diagnostic and prognostic performance. Sozzi et al (38) combined miRNA analyses with low-dose computed tomography (LDCT) for the detection of LC, which resulted in a 5 -fold reduction of the false-positive rate, from $19.4-3.7 \%$.

Protein-based detection. Protein profiling is another diagnostic method based on liquid biopsy (39). Numerous studies on LC protein biomarkers have been conducted in blood, urine, saliva and exhaled breath condensate (EBC) samples (40-42). Common protein biomarkers for LC, 


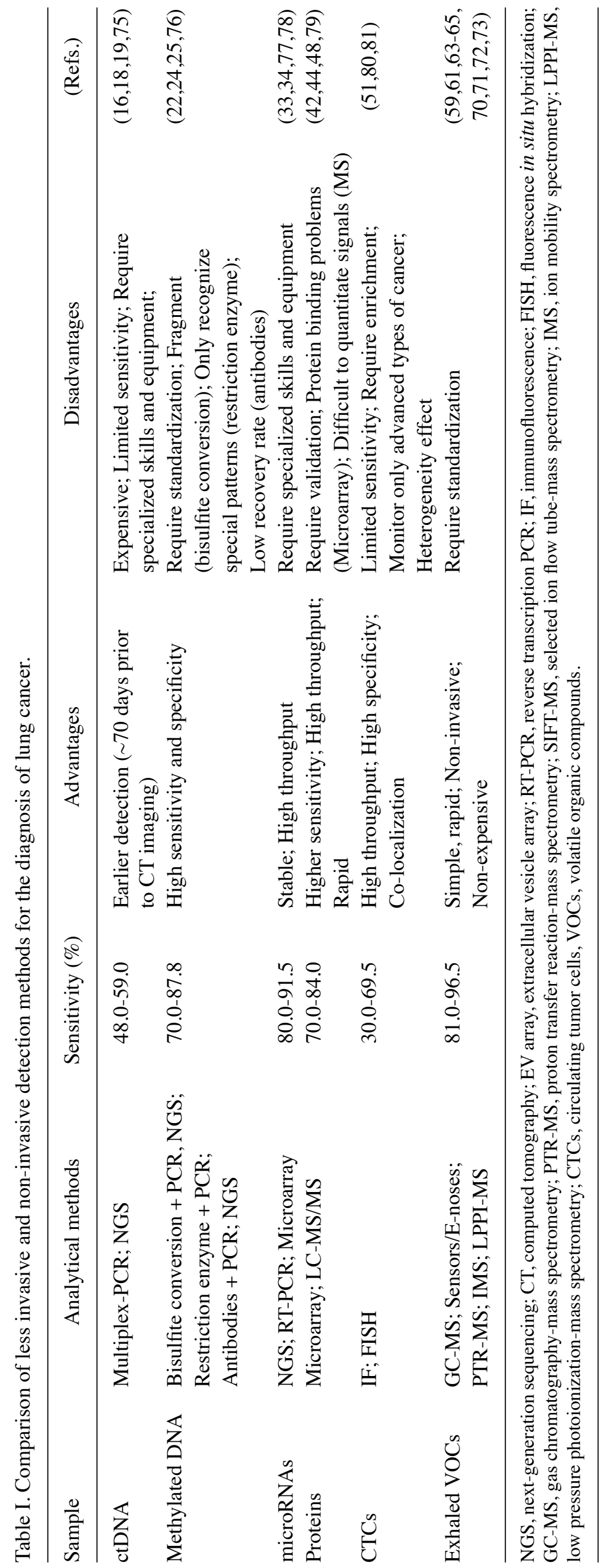


including CEA and cytokeratin fragment 21-1, are not sensitive enough to detect early tumors (43). Therefore, newer protein biomarkers with higher sensitivity have been developed. Cytoskeleton-associated protein 4 (CKAP4) is expressed at significantly higher levels in patients with LC than in the controls. In a cohort comprising 271 patients with LC and 100 healthy controls, the sensitivity of reverse-phase protein array for serum CKAP4 was $81.1 \%$. Furthermore, CKAP4 has been reported to reliably detect early-stage adenocarcinoma or squamous cell carcinoma, with a sensitivity of $78.6 \%$ (44).

Compared with traditional serological markers, exosomal proteins have certain advantages. Typically, there are over $1 \times 10^{9}$ exosomes per $\mathrm{ml}$ of human blood. Furthermore, approximately $80 \%$ salivary exosomal proteins are shared with serum exosomes (45). Several proteins are specifically expressed in exosomes, including Xbox-binding protein 1 , glypican-1 and cGMP-dependent protein kinase 1, and have shown higher sensitivity, specificity and stability compared with those in serum for cancer screening $(46,47)$. In a cohort of 109 patients with NSCLC and 110 healthy controls, the two groups were distinguished by extracellular vesicle array using the New York esophageal squamous cell carcinoma-1 protein, which was found to have $75.3 \%$ sensitivity (48). Although the mechanism of exosomal protein-based diagnosis remains unclear, these biomarkers have potential for use in the early clinical detection and diagnosis of LC, provided that they are validated.

The evaluation of proteins found in EBC, saliva and urinary samples of patients with LC is a non-invasive diagnostic method. Lopez-Sanchez et al (42) collected EBC samples from 192 individuals (48 patients; 144 healthy controls) and analyzed them by liquid chromatography-tandem mass spectrometry (LC-MS/MS). The expression levels of cytokeratins and other proteins were significantly high in LC samples, yielding $70 \%$ sensitivity and $67 \%$ specificity. Nolen et al (41) examined urinary samples of 234 individuals (83 patients; 151 healthy controls) by applying a panel of three proteins, insulin-like growth factor binding protein 1, secretory interleukin-1 receptor antagonist and cell adhesion molecule 1, to differentiate NSCLC, with $84 \%$ sensitivity and $95 \%$ specificity.

Although protein microarray analysis offers comprehensive protein information with minimal sample requirement, it could be optimized for the rapid screening of LC. However, various issues regarding protein binding remain a challenge for these protein detection arrays (49). Moreover, LC-MS/MS is an excellent detection method for systematic analysis of protein profiling of LC, though not a rapid and high-throughput platform in translational medicine.

Cell-based detection. Tumors release certain malignant cells, termed CTCs, into the vasculature. CTCs have been characterized based on their migration and invasion abilities in the early stages of LC. High CTC numbers correspond to an aggressive type of cancer, increased metastasis and increased likelihood of relapse (50). Nevertheless, the number of CTCs in patients may be as low as 1 CTC per ml of blood. Therefore, cell enrichment is required, which typically depends on the antigens, e.g., EpCAM and CD45, or inherent properties of CTCs, including size, deformability or dielectric susceptibility (51). Following cell enrichment, verification of CTCs is generally achieved by high-resolution imaging combined with immunohistochemical enumeration.

The CellSearch ${ }^{\circledR}$ test (Menarini Silicon Biosystems, Inc.), which is EpCAM-dependent, is the only FDA-approved method for CTC detection that has been proven to provide prognostic information in metastatic breast, colorectal and prostate cancer. Regarding LC, however, this method has been found to exhibit limited detection efficiency (52). In a cohort of 150 patients with LC, the sensitivity of CellSearch ${ }^{\circledR}$ was only $30.4 \%$ (53). In another study, a novel, size-based filtration platform was employed for the diagnosis of LC in 82 patients, which was shown to have improved sensitivity for CTC detection (69.5\%) (54).

CTC-based liquid biopsy has several advantages, including high specificity, demonstrating the localization signal as an integrated cell. However, the use of CTCs for LC screening is currently impaired by its limited application in the clinical setting. As negligible CTC counts are found in early-stage patients with LC, CTC detection methods may only be efficient for patients with advanced LC $(54,55)$.

VOC-based detection. VOCs are a group of gaseous organic molecules with relatively high vapor pressure or volatility. VOCs present in bodily fluids reach the lungs via the bloodstream and are exhaled through breath (15). Among them, exogenous VOCs derived from cigarette smoke, pollution and radiation target and damage DNA, proteins and polyunsaturated fatty acids (PUFAs) in the body, thus boosting oxidative stress and contributing to cancer development (56). By contrast, endogenous VOCs are mainly derived from diverse metabolic pathways. Since endogenous VOCs associated with certain metabolism may be altered by diseases, different VOC profiles have been associated with various diseases, including cancer (57).

A wide range of analytical techniques has been used for the determination of volatile metabolites. Gas chromatography-mass spectrometry (GC-MS) is considered the gold standard for the detection of specific VOCs (58-60). Phillips et al $(61,62)$ applied the predictive model of 16 and 30 VOCs to differentiate patients with primary LC from the controls in a cohort of 193 patients and 211 controls and it was found that this model had approximately $85 \%$ sensitivity and approximately $80 \%$ specificity. In another cohort consisting of 88 patients and 155 controls, three diagnostic models based on 23 VOCs were able to easily identify patients, with $96.5 \%$ sensitivity and $97.5 \%$ specificity (63).

Nonetheless, GC-MS is a method based on offline analyses, which requires time-consuming preparations. On the contrary, certain advanced analytical techniques, including proton transfer reaction-mass spectrometry (PTR-MS), selected ion flow tube-mass spectrometry (SIFT-MS) and low-pressure photoionization-mass spectrometry (LPPI-MS) offer real-time analysis and high sensitivity (64-66). However, to the best of our knowledge, no systematic studies have been performed for the discrimination of patients with LC by PTR-MS, SIFT-MS or LPPI-MS.

Mass spectrometry-based techniques are expensive and require complex instruments. By contrast, sensors/E-noses show great potential for fast, easy and cost-effective diagnosis and screening of LC (67). With the advancement of sensing devices, electronics and signal processing, the sizes of 
sensors/E-nose systems can be minimized along with fast data processing to provide real-time results (67). When combined with pattern recognition methods, sensors/E-noses are capable of distinguishing the exhaled breath of patients with LC from the breath of healthy controls without the need for dehumidification or pre-concentration of biomarkers (68). Nevertheless, more subjects are needed in order to increase the sensitivity and negative predictive value (69). Chang et al (11) examined the breath samples of 37 patients with LC and 48 healthy controls using a sensor system, which was found to have $79.0 \%$ sensitivity and $72.0 \%$ specificity. Gasparri et al (70) reported the differentiation of 70 patients with LC from 76 healthy controls with $81 \%$ sensitivity and $91 \%$ specificity, using a gas sensor array composed of a matrix of eight quartz microbalances. Shehada et al (71) collected breath samples from 149 volunteers with LC, specifically 40 patients with gastric cancer, 56 volunteers with non-cancerous lung diseases (asthma, chronic obstructive pulmonary disease or both) and 129 healthy controls. The self-developed silicon nanowire field effect transistor was used to separate patients with LC from subjects in the control group and were shown to have $87 \%$ sensitivity and $82 \%$ specificity.

Similarly, ion mobility spectrometry (IMS) also allows pattern recognition, rather than specific VOC identification, and has the potential for miniaturization. Handa et al (72) investigated the breath samples of 50 patients with LC and 39 healthy controls by IMS and revealed that this method had a sensitivity of $81.3 \%$ and specificity of $89.7 \%$. Nonetheless, sensors and IMS are limited in terms of detection and, thus, are usually coupled with complex algorithms (72-74). The advantages and disadvantages of nucleic acid-based (75-78), protein-based (79) and cell-based $(80,81)$ detections were compared with VOC-based detection as displayed in Table I.

\section{Targeted therapies based on non-invasive detection}

Liquid biopsy-guided therapies. A liquid biopsy, which is a non-invasive sampling procedure, is preferred for metastatic LC in order to obtain the molecular characterization (Table II). Several targeted methods, including PCR, NGS and immuno-oncology, are employed to detect gene mutation targets ( $E G F R, A L K, B R A F)$ from DNA/RNA or CTC samples (82). The application of liquid biopsy as a guidance for targeted therapy would notably improve the overall survival of patients with LC.

i) EGFR mutation. Mutations in EGFR are the only standardized therapeutic targets examined in clinical practice. COBAS (Roche Diagnostics) and Therascreen ${ }^{\circledR}$ RGQ PCR kit (Qiagen, Inc.) are two methods used for the detection of EGFR mutations, which have been approved by the FDA in the USA (83). EGFR mutations are mostly detected in DNA samples extracted from plasma. By contrast, CTC-based detection is limited by poor sensitivity and specificity and the small quantity of CTCs in blood (84). EGFR mutations occur in $20-76 \%$ patients with NSCLC and are more common among patients from the Asia-Pacific region (85). Patients with LC, who have $E G F R$ mutations, are normally treated with tyrosine kinase inhibitors (TKIs), including gefitinib, erlotinib and afatinib (86). However, sensitivity to TKI treatment varies with the type of EGFR mutation (87,88). Monoclonal antibodies and TKIs are usually applied to treat specific genetic alterations, including $E G F R$ and $A L K$, in both the first line and resistant settings $(89,90)$. Several new generation TKIs (e.g., osimertinib, olmutinib, nazartinib, avitinib and rociletinib) have been developed for patients harboring EGFR resistance mutations $(5,91)$. In general, EGFR mutations that confer sensitivity to TKI therapy seem to be greater than those that confer resistance (92).

ii) $A L K$ rearrangement. $A L K$ rearrangements act as an oncogenic driver in 4-6\% of NSCLCs (93). Several target methods are used to evaluate the status of $A L K$ by liquid biopsy, including RT-PCR, NGS, and fluorescence in situ hybridization. However, during the preprocessing steps, circulating plasma RNAs are degraded rapidly, which results in lower sensitivity $(94,95)$. Conversely, CTC-based detection of $A L K$ status is more feasible and in accordance with tissue biopsies (96). Previous studies have evaluated several types of $A L K$ inhibitors, including crizotinib, alectinib, ceritinib and lorlatinib in patients with LC/NSCLC (97-100). Most patients with NSCLC that have $A L K$ rearrangements respond well to $A L K$ TKIs; heterogeneous responses are also reported, though the reason remains unknown (101).

iv) BRAF mutations. BRAF mutations can be identified in $1.6-1.8 \%$ of patients with LC (102). These mutations act as an oncogenic driver in NSCLC via the mitogen-activated protein kinase (MAPK) pathway. Vemurafenib and dabrafenib are used to block MAPK signaling in patients with LC (103). Furthermore, since these mutations increase the kinase activity of $B R A F$ towards mitogen-activated protein kinase (MAPK) kinase $(M E K)$, the combination of MAPK pathway inhibition with $B R A F$ and $M E K$ inhibitors may prove to be an effective therapeutic strategy for LC. $B R A F$ mutations can be detected in plasma DNA or CTC samples. It has been reported that the combination of dabrafenib and trametinib (a selective allosteric inhibitor of MEK1/MEK2) (104) showed robust antitumor activity and a manageable safety profile in patients with NSCLC that harbored BRAF mutations (105).

Apart from the main oncogenic mutations that were mentioned above, additional molecular targets for LC have been identified, including ROS proto-oncogene 1, human epidermal growth factor receptor 2, phosphatidylinositol-4,5-bisphosphate 3-kinase catalytic subunit alpha, rearranged during transfection proto-oncogene and hepatocyte growth factor receptor (106-108). Although several monoclonal antibodies and tyrosine-kinase inhibitor drugs have been developed to inhibit LC-related signaling pathways, there is an urgent need for the development of detection methods with improved sensitivity for the determination of specific biomarkers and guidance of effective treatment options.

VOC production mechanisms and their potential for targeted therapies. Different VOCs may contain metabolic information concerning various types of human tissues and the storage capacities of volatile organic substances significantly differ in different types of human tissues. The time required to metabolize these different VOCs from the human body also differs (109). Preliminary metabolic pathways of several VOCs that have been studied include the following: i) Hydrocarbons; ii) alcohols; iii) aldehydes; iv) branched aldehydes; v) ketones; vi) esters; vii) nitriles and aromatics.

i) Hydrocarbon. In the human body, oxidative stress is the main mechanism corresponding to the production of 
Table II. Comparison of the main targeted therapies guided by liquid biopsy.

\begin{tabular}{|c|c|c|c|c|}
\hline Target & Frequency $(\%)$ & Drug used & Detection & (Refs.) \\
\hline$E G F R$ mutation & $20-76$ & Gefitinib, erlotinib, afatinib, osimertinib & Plasma DNA; CTCs & $(84,85,91)$ \\
\hline$A L K$ rearrangement & $4-6$ & Crizotinib, Alecc, Ceritinib, Lorlatinib. & Plasma DNA/RNA; CTCs & $(93,96,97)$ \\
\hline$B R A F$ mutation & $1.6-1.8$ & Vemurafenib, dabrafenib sorafenib, trametinib & Plasma DNA; CTCs & $(102-105)$ \\
\hline
\end{tabular}

CTCs, circulating tumor cells; EGFR, epidermal growth factor receptor; $A L K$, anaplastic lymphoma kinase.

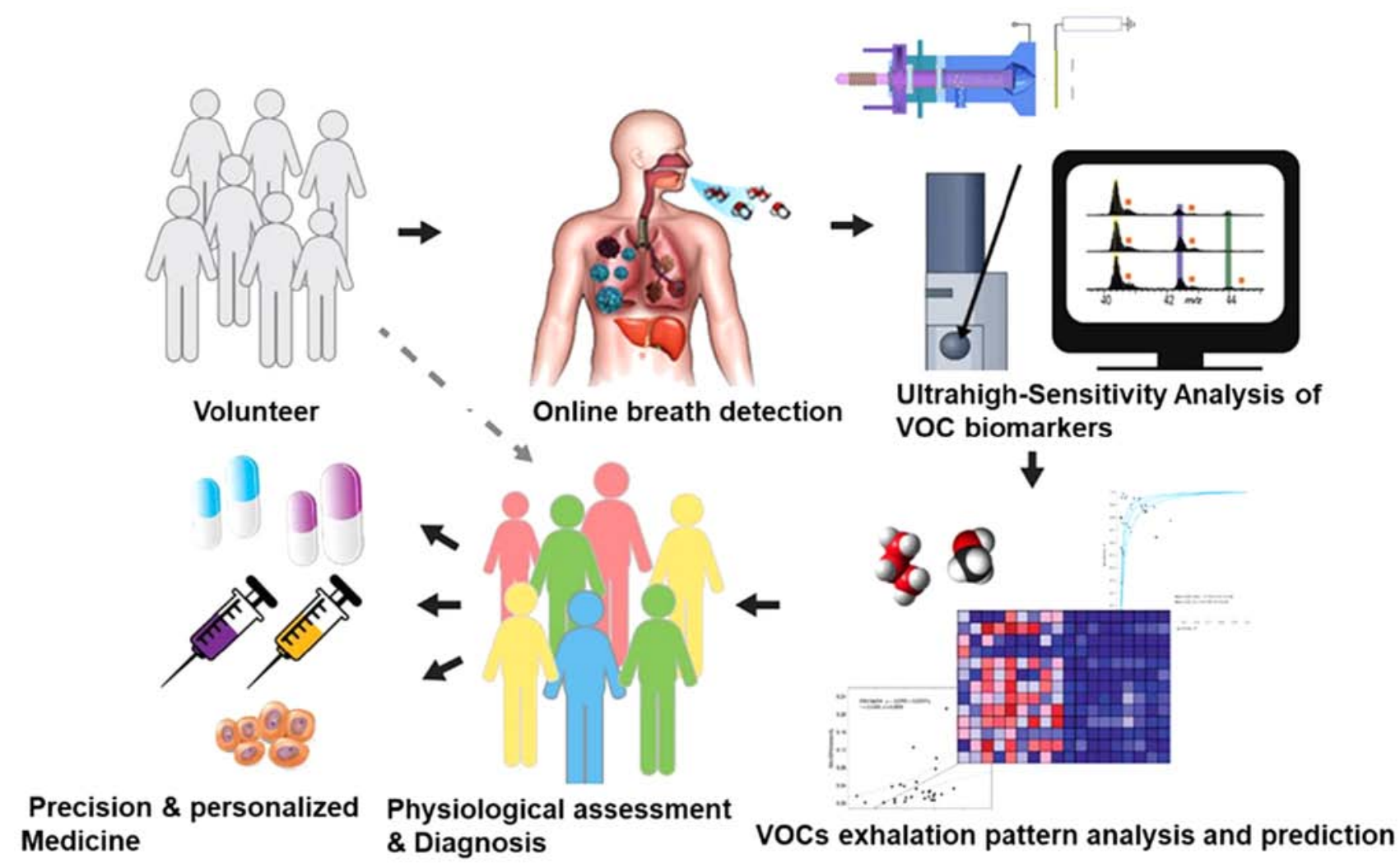

Figure 1. Process of VOC biomarker-based targeted therapies for patients with lung cancer. VOC, volatile organic compound.

hydrocarbons. Alkanes are mainly derived from the peroxidation of PUFAs, which occurs in the cell and subcellular membranes. Lipid peroxidation can cause tissue damage, which in turn may lead to aging, inflammation, atherosclerosis, and cancer. The effects of lipid peroxidation may be reduced and regulated by antioxidants (57). Saturated alkanes including ethane and pentane are considered the final products of lipid peroxidation and have been widely recognized as volatile biomarkers of this reaction in breath analysis (110). The production of $\mathrm{C} 3-\mathrm{C} 11$ saturated alkanes is also associated with lipid peroxidation, though the production of branched alkanes does not originate from this mechanism (111). As hydrocarbons have a lower solubility in blood, they can be excreted from the body by exhaled breath in a matter of minutes (112).

ii) Alcohols. Alcohols are also considered products of hydrocarbon metabolism and can be easily absorbed in the digestive tract. Once absorbed, alcohols enter the bloodstream. As short-chain alcohols are highly soluble in water, their absorption into the bloodstream is rapid. The metabolism of alcohols varies greatly due to the diversity of fat and water content among individuals. Certain enzymes, including alcohol dehydrogenase and cytochrome p450 family 2 subfamily E member 1 (CYP2E1), which is mainly expressed in the liver, are involved in the metabolism of alcohols (57).

iii) Aldehydes.Aldehydes may be produced through normal physiological processes. Certain aldehydes serve important roles in the physiological functions of the body, whereas others are considered to be cytotoxic intermediates that perform specific functions and serve roles in signal transmission, gene regulation and cell proliferation $(113,114)$. In the human body, aldehydes may be derived from multiple processes or sources, including the following: i) Alcohol metabolism; ii) degradation of hydrogen peroxide-containing substances by CYP2E1, a by-product of lipid peroxidation (115); iii) smoking, which produces a large number of aldehydes; saturated and unsaturated aldehydes, including formaldehyde, acetaldehyde, and acrolein, are produced from tobacco burning (116); iv) by-products of tobacco metabolism, which occurs in the 
cytochrome, which in turn participates in detoxification (117); v) dietary intake (118).

iv) Ketones. Fatty acid oxidation in the body is accelerated with the onset of cancer. As a result, a large number of ketones are identified in cancer patients, the production of which is closely related to the rapid decline of weight, a common complication of cancer. The liver is a vital organ for ketone metabolism (119). Since a considerable amount of acetoacetate and b-hydroxybutyric acid are synthesized in the liver, acetoacetate spontaneously undergoes decarboxylation and acetone is consequently produced (120).

v) Esters. Large amounts of exogenous esters are found in natural fats, oils, natural waxes and plant essential oils. In the human body, esterases are capable of hydrolyzing esters to alcohols and acids at body temperature, which is similar to the process by which lipases hydrolyze fat (121).

vi) Nitriles and aromatic substances. Nitriles and aromatic substances enter the human body via external pollutants, including air pollution, drinking, smoking and radiation. Due to their carcinogenicity, they have gained interest in the study of cancer (11). They are highly active and can cause damage to PUFAs, proteins and DNA. As these damages accumulate in the body, normal repair functions cease to be effective, leading to the development of a series of diseases, including cancer.

Studying the VOC- and metabolite- profiles of LC cells provides an alternative to invasive diagnosis. A recent study revealed a possible association between VOCs and metabolites. It was found that the combination of benzaldehyde, 2-ethylhexanol and 2,4-decadien-1-ol could serve as potential VOC biomarkers for LC (122). These VOCs are also strongly negatively associated with the levels of certain amino acids, glucose, cholesterol and several fatty acids. Another study examined the VOC biomarkers that were associated with EGFR, KRAS and $A L K$ mutations in LC cell lines. Triethylamine, benzaldehyde and decanal have the potential to become specific VOC biomarkers for identifying and distinguishing these mutations in patients with LC (123). Further clinical studies are required to determine whether these cell-line methods could be translated into clinical diagnostic tools.

The goal of personalized medicine is to treat patients using their genetic profile. The gene-specific VOC biomarkers are metabolized in different types of tissues, transported to the lungs via blood circulation and exhaled from the alveoli. These exhaled breath-detection methods are entirely non-invasive, readily available and do not require any preparation (57). Therefore, they have the potential to provide indirect genetic and pathological information prior to and during the treatment period.

In order to validate the efficacy of VOC profiles in the exhaled breath as a means of diagnosing LC, advancements in the following technologies are critically required: i) Standardized clinical utility; and ii) advanced mass spectrometry with ultra-high sensitivity. Recently, the excited state proton transfer (ESPT) ionization technology was established by LPPI-MS, discovering new mechanisms of chemi-ionization reactions and offering new technological applications that have the potential to greatly improve mass spectrometry sensitivity for detecting trace gaseous organics $(124,125)$. VUV excitation is applied to produce a chemi-ionization reaction, which yields substantial $\mathrm{H}_{3} \mathrm{O}^{+}$ ions, and the protonated analyte, an equal amount of $\mathrm{Cl}^{-}$, may be produced with the aid of the reorganization energy released from the formation of $\mathrm{CH}_{2} \mathrm{O}$ and $\mathrm{HCl}$. The sensitivity for VOC biomarkers is at least 20 times higher than that for PTR-MS. Regarding oxygenated VOCs, the signal intensities of oxygenated organics can be amplified by more than two orders of magnitude.

The application of advanced techniques in volatile fingerprinting, allows non-invasive, rapid and accurate detection, thereby leading to early diagnosis and prognosis based on metabolomics. The process of VOC biomarker-based targeted therapies for patients with LC is presented in Fig. 1. First, patients with LC and other lung diseases and healthy controls are recruited. Secondly, exhaled breath samples are collected from the volunteers and VOC biomarkers are analyzed using ultra-high-sensitivity techniques, including ESPT ionization. Subsequently, machine learning algorithms are employed for the data mining of VOC profiles. In combination with routine diagnostic methods, physiological assessment and diagnosis are accomplished using VOC biomarkers. Improved precision of diagnostic techniques and personalized medicine could lead to the identification of additional VOC biomarkers and are anticipated to open up connections between omics technologies (genomics, proteomics and metabolomics), which may result in the faster and more efficient discovery of other molecular markers and intervening targets.

\section{Challenges and future directions}

Despite the vast potential of existing candidates and methodologies, only a few non-invasive detection methods for LC, including the Guardant $360{ }^{\circledR}$ panel (http://www.guardant360. com) and cobas ${ }^{\circledR} E G F R$ Mutation Test v2 (Roche Molecular Diagnostics) are currently being used in the clinical setting. In order to apply potential non-invasive detection methods to clinical practice, several milestones must be achieved. First, head-to-head comparisons of different types of biomarkers in specific clinical scenarios would be beneficial. Deep mining of data provided by machine learning would also be useful. Secondly, the instrumentation used for biomarker detection requires careful reevaluation. Mass spectrometry, NGS, PCR, microarray and LDCT are standard techniques that are widely used in biomarker detection. However, in order to obtain accurate results in clinical practice, the reliability of instruments and reproducibility of results should be examined and optimized in clinical studies. Thirdly, the interactions between liquid biopsy, imaging and VOC biomarkers should also be identified in clinical studies. Moreover, the combination of different biomarker tests could reduce false-positive results and enable greater standardization of diagnostic algorithms, thereby decreasing health care costs.

Although recent advances in the field of oncogenic gene mutations have made it possible to realize molecular-targeted therapy, monitoring the VOC signatures associated with cancer-specific genetic mutations may be a faster and easier method than conventional gene profiling. This technique would aid the improvement of drug selection and detection of resistance, thereby increasing the clinical benefits for patients with LC through safer, more timely and effective interventions that could improve their overall survival and quality of life. 


\section{Acknowledgements}

Not applicable.

\section{Funding}

The present study was funded by the National Natural Science Foundation of China (grant no. 81802981) and the Beijing Municipal Science \& Technology Commission (grant no. Z181100003818008).

\section{Availability of data and materials}

Not applicable.

\section{Authors' contributions}

ZL contributed to the design and writing of the manuscript, with support from ZZ and JH. BY and YC drafted the initial manuscript and revised it critically for important intellectual content. JS made substantial contributions to conception and design, and gave final approval of the version to be published. All authors read and approved the final manuscript.

\section{Ethics approval and consent to participate}

Not applicable.

\section{Patient consent for publication}

Not applicable.

\section{Competing interests}

The authors declare that they have no competing interests.

\section{References}

1. Bray F, Ferlay J, Soerjomataram I, Siegel RL, Torre LA and Jemal A: Global cancer statistics 2018: GLOBOCAN estimates of incidence and mortality worldwide for 36 cancers in 185 countries. CA Cancer J Clin 68: 394-424, 2018.

2. Calvayrac O, Pradines A, Pons E, Mazieres J and Guibert N: Molecular biomarkers for lung adenocarcinoma. Eur Respir J 49: 1601734, 2017.

3. Hyman DM, Puzanov I, Subbiah V, Faris JE, Chau I, Blay JY, Wolf J, Raje NS, Diamond EL, Hollebecque A, et al: Vemurafenib in multiple nonmelanoma cancers with BRAF V600 mutations. N Engl J Med 373: 726-736, 2015.

4. PaoW,Miller V,Zakowski M,Doherty J,PolitiK,Sarkaria I,Singh B, Heelan R, Rusch V, Fulton L, et al: EGF receptor gene mutations are common in lung cancers from 'never smokers' and are associated with sensitivity of tumors to gefitinib and erlotinib. Proc Natl Acad Sci USA 101: 13306-13311, 2004.

5. Walter AO, Sjin RT, Haringsma HJ, Ohashi K, Sun J, Lee K, Dubrovskiy A, Labenski M, Zhu Z, Wang Z, et al: Discovery of a mutant-selective covalent inhibitor of EGFR that overcomes T790M-mediated resistance in NSCLC. Cancer Discov 3: 1404-1415, 2013.

6. Dugay F, Llamas-Gutierrez F, Gournay M, Medane S, Mazet F, Chiforeanu DC, Becker E, Lamy R, Léna H, Rioux-Leclercq N, et al: Clinicopathological characteristics of ROS1- and RET-rearranged NSCLC in caucasian patients. Data from a cohort of 713 non-squamous NSCLC lacking KRAS/EGFR/HER2/BRAF/PIK3CA/ALK alterations. Oncotarget 8: 53336-53351, 2017.
7. Doseeva V, Colpitts T, Gao G, Woodcock J and Knezevic V: Performance of a multiplexed dual analyte immunoassay for the early detection of non-small cell lung cancer. J Transl Med 13: $55,2015$.

8. Plaks V, Koopman CD and Werb Z: Cancer. Circulating tumor cells. Science 341: 1186-1188, 2013.

9. Rocco G, Pennazza G, Santonico M, Longo F, Rocco R, Crucitti P and Antonelli Incalzi R: Breathprinting and early diagnosis of lung cancer. J Thorac Oncol 13: 883-894, 2018.

10. van der Schee MP, Paff T, Brinkman P, van Aalderen WMC, Haarman EG and Sterk PJ: Breathomics in lung disease. Chest 147: 224-231, 2015.

11. Chang JE, Lee DS, Ban SW, Oh J, Jung MY, Kim SH, Parka S, Persaude K and Jheon S: Analysis of volatile organic compounds in exhaled breath for lung cancer diagnosis using a sensor system. Sensors Actuators B Chem 255: 800-807, 2018.

12. Chae YK and Oh MS: Detection of minimal residual disease using ctDNA in lung cancer: Current evidence and future directions. J Thorac Oncol 14: 16-24, 2019.

13. Hou JM, Krebs M, Ward T, Sloane R, Priest L, Hughes A, Clack G, Ranson M, Blackhall F and Dive C: Circulating tumor cells as a window on metastasis biology in lung cancer. Am J Pathol 178: 989-996, 2011.

14. Ma S, Wang W, Xia B, Zhang S, Yuan H, Jiang H, Meng W, Zheng $X$ and Wang X: Multiplexed serum biomarkers for the detection of lung cancer. EBioMedicine 11: 210-218, 2016.

15. Haick H, Broza YY, Mochalski P, Ruzsanyi V and Amann A: Assessment, origin, and implementation of breath volatile cancer markers. Chem Soc Rev 43: 1423-1449, 2014.

16. Fiala $C$ and Diamandis EP: Circulating tumor DNA for personalized lung cancer monitoring. BMC Med 15: 157, 2017.

17. Diehl F, Schmidt K, Choti MA, Romans K, Goodman S, Li M, Thornton K, Agrawal N, Sokoll L, Szabo SA, et al: Circulating mutant DNA to assess tumor dynamics. Nat Med 14: 985-990, 2008.

18. Abbosh C, Birkbak NJ, Wilson GA, Jamal-Hanjani M, Constantin T, Salari R, Le Quesne J, Moore DA, Veeriah S, Rosenthal R, et al: Corrigendum: Phylogenetic ctDNA analysis depicts early-stage lung cancer evolution. Nature 554: 264, 2018.

19. Cohen JD, Li L, Wang Y, Thoburn C, Afsari B, Danilova L, Douville C, Javed AA, Wong F, Mattox A, et al: Detection and localization of surgically resectable cancers with a multi-analyte blood test. Science 359: 926-930, 2018.

20. Ehrlich M: DNA hypomethylation in cancer cells. Epigenomics 1: 239-259, 2009.

21. Ooki A, Maleki Z, Tsay JJ, Goparaju C, Brait M, Turaga N, Nam HS, Rom WN, Pass HI, Sidransky D, et al: A Panel of novel detection and prognostic methylated DNA markers in primary non-small cell lung cancer and serum DNA. Clin Cancer Res 23: 7141-7152, 2017.

22. Wielscher M, Vierlinger K, Kegler U, Ziesche R, Gsur A and Weinhausel A: Diagnostic performance of plasma DNA methylation profiles in lung cancer, pulmonary fibrosis and COPD. EBioMedicine 2: 929-936, 2015.

23. Ilse P, Biesterfeld S, Pomjanski N, Wrobel C and Schramm M: Analysis of SHOX2 methylation as an aid to cytology in lung cancer diagnosis. Cancer Genomics Proteomics 11: 251-258, 2014.

24. Zhao QT, Guo T, Wang HE, Zhang XP, Zhang H, Wang ZK, Yuan Z and, Duan GC: Diagnostic value of SHOX2 DNA methylation in lung cancer: A meta-analysis. Onco Targets Ther 8: 3433-3439, 2015

25. Lu Y, Li S, Zhu S, Gong Y, Shi J and Xu L: Methylated DNA/RNA in body fluids as biomarkers for lung cancer. Biol Proced Online 19: 2, 2017.

26. Hernandez HG, Tse MY, Pang SC, Arboleda H and Forero DA: Optimizing methodologies for PCR-based DNA methylation analysis. Biotechniques 55: 181-197, 2013.

27. Huang ZH, Hu Y, Hua D, Wu YY, Song MX and Cheng ZH: Quantitative analysis of multiple methylated genes in plasma for the diagnosis and prognosis of hepatocellular carcinoma. Exp Mol Pathol 91: 702-707, 2011.

28. Chen B, Li H, Zeng X, Yang P, Liu X, Zhao X and Liang S: Roles of microRNA on cancer cell metabolism. J Transl Med 10: 228, 2012.

29. Yanaihara N, Caplen N, Bowman E, Seike M, Kumamoto K, Yi M, Stephens RM, Okamoto A, Yokota J, Tanaka T, et al: Unique microRNA molecular profiles in lung cancer diagnosis and prognosis. Cancer Cell 9: 189-198, 2006.

30. Kim H, Yang JM, Jin Y, Jheon S, Kim K, Lee CT, Chung JH and Paik JH: MicroRNA expression profiles and clinicopathological implications in lung adenocarcinoma according to EGFR, KRAS, and ALK status. Oncotarget 8: 8484-8498, 2017. 
31. Li D, Wei Y, Wang D, Gao H and Liu K: MicroRNA-26b suppresses the metastasis of non-small cell lung cancer by targeting MIEN1 via NF-KB/MMP-9/VEGF pathways. Biochem Biophys Res Commun 472: 465-470, 2016.

32. Dacic S, Kelly L, Shuai Y and Nikiforova MN: MiRNA expression profiling of lung adenocarcinomas: Correlation with mutational status. Mod Pathol 23: 1577-1582, 2010.

33. Lu S, Kong H, Hou Y, Ge D, Huang W, Ou J, Yang D, Zhang L, $\mathrm{Wu} \mathrm{G}$, Song Y, et al: Two plasma microRNA panels for diagnosis and subtype discrimination of lung cancer. Lung Cancer 123 : 44-51, 2018.

34. Leng Q, Lin Y, Jiang F, Lee CJ, Zhan M, Fang H, Wang Y and Jiang F: A plasma miRNA signature for lung cancer early detection. Oncotarget 8: 111902-111911, 2017.

35. Arab A, Karimipoor M, Irani S, Kiani A, Zeinali S, Tafsiri E and Sheikhy K: Potential circulating miRNA signature for early detection of NSCLC. Cancer Genet 216-217: 150-158, 2017.

36. Halvorsen AR, Bjaanaes M, LeBlanc M, Holm AM, Bolstad N, Rubio L, Peñalver JC, Cervera J, Mojarrieta JC, López-Guerrero JA, et al: A unique set of 6 circulating microRNAs for early detection of non-small cell lung cancer. Oncotarget 7: 37250-37259, 2016.

37. Ma J, Mannoor K, Gao L, Tan A, Guarnera MA, Zhan M, Shetty A, Stass SA, Xing L and Jiang F: Characterization of microRNA transcriptome in lung cancer by next-generation deep sequencing. Mol Oncol 8: 1208-1219, 2014.

38. Sozzi G, Boeri M, Rossi M, Verri C, Suatoni P, Bravi F, Roz L, Conte D, Grassi M, Sverzellati N, et al: Clinical utility of a plasma-based miRNA signature classifier within computed tomography lung cancer screening: A correlative MILD trial study. J Clin Oncol 32: 768-773, 2014.

39. Molina-Vila MA: Liquid biopsy in lung cancer: Present and future. Transl Lung Cancer Res 5: 452-454, 2016.

40. Han MK, Oh YH, Kang J, Kim YP, Seo S, Kim J, Park K and Kim HS: Protein profiling in human sera for identification of potential lung cancer biomarkers using antibody microarray. Proteomics 9: 5544-5552, 2009.

41. Nolen BM, Lomakin A, Marrangoni A, Velikokhatnaya L, Prosser D and Lokshin AE: Urinary protein biomarkers in the early detection of lung cancer. Cancer Prev Res (Phila) 8 : $111-119,2015$.

42. Lopez-Sanchez LM, Jurado-Gamez B, Feu-Collado N Valverde A, Canas A, Fernandez-Rueda JL, Aranda E and Rodríguez-Ariza A: Exhaled breath condensate biomarkers for the early diagnosis of lung cancer using proteomics. Am J Physiol Lung Cell Mol Physiol 313: L664-L676, 2017.

43. Jung M, Kim SH, Lee YJ, Hong S, Kang YA, Kim SK, Chang J, Rha SY, Kim JH, Kim DJ and Cho BC: Prognostic and predictive value of CEA and CYFRA 21-1 levels in advanced non-small cell lung cancer patients treated with gefitinib or erlotinib. Exp Ther Med 2: 685-693, 2011.

44. Yanagita K, Nagashio R, Jiang SX, Kuchitsu Y, Hachimura K Ichinoe M, Igawa S, Fukuda E, Goshima N, Satoh Y, et al: Cytoskeleton-Associated protein 4 is a novel serodiagnostic marker for lung cancer. Am J Pathol 188: 1328-1333, 2018.

45. Sun Y, Liu S, Qiao Z, Shang Z, Xia Z, Niu X, Qian L, Zhang Y, Fan L, Cao CX and Xiao H: Systematic comparison of exosomal proteomes from human saliva and serum for the detection of lung cancer. Anal Chim Acta 982: 84-95, 2017

46. Melo SA, Luecke LB, Kahlert C, Fernandez AF, Gammon ST, Kaye J, LeBleu VS, Mittendorf EA, Weitz J, Rahbari N, et al: Glypican-1 identifies cancer exosomes and detects early pancreatic cancer. Nature 523: 177-182, 2015.

47. Chen IH, Xue L, Hsu CC, Paez JS, Pan L, Andaluz H, Wendt MK, Iliuk AB, Zhu JK and Tao WA: Phosphoproteins in extracellular vesicles as candidate markers for breast cancer. Proc Natl Acad Sci USA 114: 3175-3180, 2017

48. Jakobsen KR, Paulsen BS, Baek R, Varming K, Sorensen BS and Jorgensen MM: Exosomal proteins as potential diagnostic markers in advanced non-small cell lung carcinoma. J Extracell Vesicles 4: 26659, 2015.

49. Kodadek T: Protein microarrays: Prospects and problems. Chem Biol 8: 105-115, 2001

50. Chaffer CL and Weinberg RA: A perspective on cancer cell metastasis. Science 331: 1559-1564, 2011.

51. Joosse SA, Gorges TM and Pantel K: Biology, detection, and clinical implications of circulating tumor cells. EMBO Mol Med 7: 1-11,2015

52. Hamilton G and Rath B: Detection of circulating tumor cells in non-small cell lung cancer. J Thorac Dis 8: 1024-1028, 2016.
53. Tanaka F, Yoneda K, Kondo N, Hashimoto M, Takuwa T, Matsumoto S, Okumura Y, Rahman S, Tsubota N, Tsujimura T, et al: Circulating tumor cell as a diagnostic marker in primary lung cancer. Clin Cancer Res 15: 6980-6986, 2009.

54. Sonn CH, Cho JH, Kim JW, Kang MS, Lee J and Kim J: Detection of circulating tumor cells in patients with non-small cell lung cancer using a size-based platform. Oncol Lett 13: 2717-2722, 2017.

55. Truini A, Alama A, Dal Bello MG, Coco S, Vanni I, Rijavec E, Genova C, Barletta G, Biello F and Grossi F: Clinical applications of circulating tumor cells in lung cancer patients by cell search system. Front Oncol 4: 242, 2014.

56. Ambrosone CB: Oxidants and antioxidants in breast cancer. Antioxid Redox Signal 2: 903-917, 2000.

57. Hakim M, Broza YY, Barash O, Peled N, Phillips M, Amann A, Haick H: Volatile organic compounds of lung cancer and possible biochemical pathways. Chem Rev 112: 5949-5966, 2012.

58. Filipiak W, Sponring A, Filipiak A, Ager C, Schubert J, Miekisch W, Amann A and Troppmair J: TD-GC-MS analysis of volatile metabolites of human lung cancer and normal cells in vitro. Cancer Epidemiol Biomarkers Prev 19: 182-195, 2010.

59. Buszewski B, Ligor T, Jezierski T, Wenda-Piesik A, Walczak M and Rudnicka J: Identification of volatile lung cancer markers by gas chromatography-mass spectrometry: Comparison with discrimination by canines. Anal Bioanal Chem 404: 141-146, 2012.

60. Rudnicka J, Walczak M, Kowalkowski T, Jezierski T and Buszewski B: Determination of volatile organic compounds as potential markers of lung cancer by gas chromatography-mass spectrometry versus trained dogs. Sensors Actuators B Chem 202: 615-621, 2014

61. Phillips M, Altorki N, Austin JH, Cameron RB, Cataneo RN, Kloss R, Maxfield RA, Munawar MI, Pass HI, Rashid A, et al: Detection of lung cancer using weighted digital analysis of breath biomarkers. Clin Chim Acta 393: 76-84, 2008.

62. Phillips M, Altorki N, Austin JH, Cameron RB, Cataneo RN, Greenberg J, Kloss R, Maxfield RA, Munawar MI, Pass HI, et al: Prediction of lung cancer using volatile biomarkers in breath. Cancer Biomark 3: 95-109, 2007.

63. Wang Y, Hu Y, Wang D, Yu K, Wang L, Zou Y, Zhao C, Zhang X, Wang $P$ and Ying $K$ : The analysis of volatile organic compounds biomarkers for lung cancer in exhaled breath, tissues and cell lines. Cancer Biomark 11: 129-137, 2012.

64. Brunner C, Szymczak W, Hollriegl V, Mortl S, Oelmez H, Bergner A, Huber RM, Hoeschen C and Oeh U: Discrimination of cancerous and non-cancerous cell lines by headspace-analysis with PTR-MS. Anal Bioanal Chem 397: 2315-2324, 2010

65. Brůhová Michalčíková R, Dryahina K and Španěl P: SIFT-MS quantification of several breath biomarkers of inflammatory bowel disease, IBD: A detailed study of the ion chemistry. Int J Mass Spectrom 396: 35-41, 2016.

66. Li Z, Xu C, Shu J, Yang B and Zou Y: Doping-assisted low-pressure photoionization mass spectrometry for the real-time detection of lung cancer-related volatile organic compounds. Talanta 165: 98-106, 2017

67. Behera B, Joshi R, Anil Vishnu GK, Bhalerao S and Pandya HJ: Electronic-nose: A non-invasive technology for breath analysis of diabetes and lung cancer patients. J Breath Res 13: 024001, 2019.

68. Peng G, Tisch U, Adams O, Hakim M, Shehada N, Broza YY, Billan S, Abdah-Bortnyak R, Kuten A and Haick H: Diagnosing lung cancer in exhaled breath using gold nanoparticles. Nat Nanotechnol 4: 669-673, 2009.

69. Kort S, Brusse-Keizer M, Schouwink JH, Gerritsen JW and Van dPJ: Detection of non-small cell lung cancer by an electronic nose. Eur Respir J 50 (Suppl 61): PA2032, 2017.

70. Gasparri R, Santonico M, ValentiniC,Sedda G,Borri A,PetrellaF, Maisonneuve P, Pennazza G, D'Amico A, Di Natale C, et al: Volatile signature for the early diagnosis of lung cancer. J Breath Res 10: 016007, 2016.

71. Shehada N, Cancilla JC, Torrecilla JS, Pariente ES, Bronstrup G, Christiansen S, Johnson DW, Leja M, Davies MP, Liran O, et al: Silicon nanowire sensors enable diagnosis of patients via exhaled breath. ACS Nano 10: 7047-7057, 2016.

72. Handa H, Usuba A, Maddula S, Baumbach JI, Mineshita M and Miyazawa T: Exhaled breath analysis for lung cancer detection using ion mobility spectrometry. PLoS One 9: e114555, 2014.

73. Zhong X, Li D, Du W, Yan M, Wang Y, Huo D and Hou C: Rapid recognition of volatile organic compounds with colorimetric sensor arrays for lung cancer screening. Anal Bioanal Chem 410: 3671-3681, 2018. 
74. Queralto N, Berliner AN, Goldsmith B, Martino R, Rhodes P and Lim SH: Detecting cancer by breath volatile organic compound analysis: A review of array-based sensors. J Breath Res 8: 027112, 2014.

75. Aravanis AM, Lee M and Klausner RD: Next-Generation sequencing of circulating tumor DNA for early cancer detection. Cell 168: 571-574, 2017.

76. Wang J, Han X and Sun Y: DNA methylation signatures in circulating cell-free DNA as biomarkers for the early detection of cancer. Sci China Life Sci 60: 356-362, 2017.

77. Iqbal MA, Arora S, Prakasam G, Calin GA and Syed MA: MicroRNA in lung cancer: Role, mechanisms, pathways and therapeutic relevance. Mol Aspects Med 70: 3-20, 2019.

78. Keller A, Leidinger P, Gislefoss R, Haugen A, Langseth $\mathrm{H}$, Staehler P, Lenhof HP and Meese E: Stable serum miRNA profiles as potential tool for non-invasive lung cancer diagnosis. RNA Biol 8: 506-516, 2011

79. Li A, Zhang T, Zheng M, Liu Y and Chen Z: Exosomal proteins as potential markers of tumor diagnosis. J Hematol Oncol 10: $175,2017$.

80. Harouaka R, Kang Z, Zheng SY and Cao L: Circulating tumor cells: Advances in isolation and analysis, and challenges for clinical applications. Pharmacol Ther 141: 209-221, 2014.

81. Cabel L, Proudhon C, Gortais H, Loirat D, Coussy F, Pierga JY and Bidard FC: Circulating tumor cells: Clinical validity and utility. Int J Clin Oncol 22: 421-430, 2017.

82. Hofman P: Liquid biopsy and therapeutic targets: Present and future issues in thoracic oncology. Cancers (Basel) 9: E154, 2017.

83. Tsui DW and Berger MF: Profiling non-small cell lung cancer: From tumor to blood. Clin Cancer Res 22: 790-792, 2016.

84. Sundaresan TK, Sequist LV, Heymach JV, Riely GJ, Janne PA, Koch WH, Sullivan JP, Fox DB, Maher R, Muzikansky A, et al: Detection of T790M, the acquired resistance EGFR mutation, by tumor biopsy versus noninvasive blood-based analyses. Clin Cancer Res 22: 1103-1110, 2016.

85. Midha A, Dearden S and McCormack R: EGFR mutation incidence in non-small-cell lung cancer of adenocarcinoma histology: A systematic review and global map by ethnicity (mutMapII). Am J Cancer Res 5: 2892-2911, 2015.

86. Liang W, Wu X, Fang W, Zhao Y, Yang Y, Hu Z, Xue C, Zhang J, Zhang J, Ma Y, et al: Network meta-analysis of erlotinib, gefitinib, afatinib and icotinib in patients with advanced non-small-cell lung cancer harboring EGFR mutations. PLoS One 9: e85245, 2014.

87. Brandao EP, Pantarotto MG and Cruz M: A novel EGFR mutation in exon 18 with high sensitivity to EGFR TKI treatment with reduced dose. J Thorac Oncol 7: e32, 2012.

88. Kobayashi Y, Togashi Y, Yatabe Y, Mizuuchi H, Jangchul P, Kondo C, Shimoji M, Sato K, Suda K, Tomizawa K, et al: EGFR exon 18 mutations in lung cancer: Molecular predictors of augmented sensitivity to afatinib or neratinib as compared with first- or third-generation TKIs. Clin Cancer Res 21: 5305-5313, 2015.

89. Wang J, Wang B, Chu $\mathrm{H}$ and Yao Y: Intrinsic resistance to EGFR tyrosine kinase inhibitors in advanced non-small-cell lung cancer with activating EGFR mutations. Onco Targets Ther 9: 3711-3726, 2016.

90. Lindeman NI, Cagle PT, Beasley MB, Chitale DA, Dacic S, Giaccone G, Jenkins RB, Kwiatkowski DJ, Saldivar JS, Squire J, et al: Molecular testing guideline for selection of lung cancer patients for EGFR and ALK tyrosine kinase inhibitors: Guideline from the college of American pathologists, international association for the study of lung cancer, and association for molecular pathology. J Thorac Oncol 8: 823-859, 2013.

91. Tan CS, Kumarakulasinghe NB, Huang YQ, Ang YLE, Choo JR, Goh BC and Soo RA: Third generation EGFR TKIs: Curren data and future directions. Mol Cancer 17: 29, 2018.

92. Karachaliou N, Molina-Vila MA and Rosell R: The impact of rare EGFR mutations on the treatment response of patients with non-small cell lung cancer. Expert Rev Respir Med 9: 241-244, 2015.

93. Noh KW, Lee MS, Lee SE, Song JY, Shin HT, Kim YJ, Oh DY, Jung K, Sung M, Kim M, et al: Molecular breakdown: A comprehensive view of anaplastic lymphoma kinase (ALK)-rearranged non-small cell lung cancer. J Pathol 243: 307-319, 2017.

94. Vendrell JA, Taviaux S, Beganton B, Godreuil S, Audran P, Grand D, Clermont E, Serre I, Szablewski V, Coopman P, et al: Detection of known and novel ALK fusion transcripts in lung cancer patients using next-generation sequencing approaches. Sci Rep 7: 12510, 2017.

95. Hofman P: ALK status assessment with liquid biopsies of lung cancer patients. Cancers (Basel) 9: E106, 2017.
96. Pailler E, Oulhen M, Borget I, Remon J, Ross K, Auger N, Billiot F, Ngo Camus M, Commo F, Lindsay CR, et al: Circulating tumor cells with aberrant ALK copy number predict progression-free survival during crizotinib treatment in ALK-rearranged non-small cell lung cancer patients. Cancer Res 77: 2222-2230, 2017.

97. Passaro A, Lazzari C, Karachaliou N, Spitaleri G, Pochesci A, Catania C, Rosell R and de Marinis F: Personalized treatment in advanced ALK-positive non-small cell lung cancer: From bench to clinical practice. Onco Targets Ther 9: 6361-6376. 2016.

98. Peters S, Camidge DR, Shaw AT, Gadgeel S, Ahn JS, Kim DW, Ou SI, Pérol M, Dziadziuszko R, Rosell R, et al: Alectinib versus crizotinib in untreated ALK-Positive non-small-cell lung cancer. N Engl J Med 377: 829-838, 2017.

99. Shen L and Ji HF: Ceritinib in ALK-rearranged non-small-cell lung cancer. N Engl J Med 370: 2537, 2014

100. Waqar SN and Morgensztern D: Lorlatinib: A new-generation drug for ALK-positive NSCLC. Lancet Oncol 19: 1555-1557, 2018.

101. Kim RN, Choi YL, Lee MS, Lira ME, Mao M, Mann D, Stahl J, Licon A, Choi SJ, Van Vrancken M, et al: SEC31A-ALK fusion gene in lung adenocarcinoma. Cancer Res Treat 48: 398-402, 2016.

102. Barlesi F, Mazieres J, Merlio JP, Debieuvre D, Mosser J, Lena H, Ouafik L, Besse B, Rouquette I, Westeel V, et al: Routine molecular profiling of patients with advanced non-small-cell lung cancer: Results of a 1-year nationwide programme of the French cooperative thoracic intergroup (IFCT). Lancet 387: 1415-1426, 2016

103. Sanchez-Torres JM, Viteri S, Molina MA and Rosell R: BRAF mutant non-small cell lung cancer and treatment with BRAF inhibitors. Transl Lung Cancer Res 2: 244-250, 2013.

104. Planchard D, Groen HJM, Kim TM, Rigas JR, Souquet PJ, Baik CS, Bariesi F, Mazières J, Quoix EA, Curtis CM, et al: Interim results of a phase II study of the BRAF inhibitor (BRAFi) dabrafenib (D) in combination with the MEK inhibitor trametinib (T) in patients (pts) with BRAF V600E mutated (mut) metastatic non-small cell lung cancer (NSCLC). J Clin Oncol 33 (15 Suppl): S8006, 2015

105. Planchard D, Besse B, Groen HJM, Souquet PJ, Quoix E, Baik CS, Barlesi F, Kim TM, Mazieres J, Novello S, et al: Dabrafenib plus trametinib in patients with previously treated BRAF(V600E)-mutant metastatic non-small cell lung cancer: An open-label, multicentre phase 2 trial. Lancet Oncol 17: 984-993, 2016

106. Chuang JC, Stehr H, Liang Y, Das M, Huang J, Diehn M, Wakelee HA and Neal JW: ERBB2-Mutated metastatic non-small cell lung cancer: Response and resistance to targeted therapies. J Thorac Oncol 12: 833-842, 2017.

107. Salgia R: MET in lung cancer: Biomarker selection based on scientific rationale. Mol Cancer Ther 16: 555-565, 2017.

108. Gainor JF and Shaw AT: Novel targets in non-small cell lung cancer: ROS1 and RET fusions. Oncologist 18: 865-875, 2013.

109. Mochalski P, King J, Haas M, Unterkofler K, Amann A and Mayer G: Blood and breath profiles of volatile organic compounds in patients with end-stage renal disease. BMC Nephrol 15: 43, 2014.

110. Terelius $Y$ and Ingelman-Sundberg M: Metabolism of n-pentane by ethanol-inducible cytochrome P-450 in liver microsomes and reconstituted membranes. Eur J Biochem 161: 303-308, 1986.

111. Kohlmuller D and Kochen W: Is n-pentane really an index of lipid peroxidation in humans and animals? A methodological reevaluation. Anal Biochem 210: 268-276, 1993.

112. Risby TH and Sehnert SS: Clinical application of breath biomarkers of oxidative stress status. Free Radic Biol Med 27: 1182-1192, 1999.

113. Marchitti SA, Brocker C, Stagos D and Vasiliou V: Non-P450 aldehyde oxidizing enzymes: The aldehyde dehydrogenase superfamily. Expert Opin Drug Metab Toxicol 4: 697-720, 2008.

114. Rahman I, van Schadewijk AA, Crowther AJ, Hiemstra PS, Stolk J, MacNee W and De Boer WI: 4-Hydroxy-2-nonenal, a specific lipid peroxidation product, is elevated in lungs of patients with chronic obstructive pulmonary disease. Am J Respir Crit Care Med 166: 490-495, 2002.

115. Vaz AD and Coon MJ: Hydrocarbon formation in the reductive cleavage of hydroperoxides by cytochrome P-450. Proc Nat Acad Sci USA 84: 1172-1176, 1987

116. Branton PJ, McAdam KG, Winter DB, Liu C, Duke MG and Proctor CJ: Reduction of aldehydes and hydrogen cyanide yields in mainstream cigarette smoke using an amine functionalised ion exchange resin. Chem Cent J 5: 15, 2011. 
117. Kang JO, Slater G, Aufses AH Jr and Cohen G: Production of ethane by rats treated with the colon carcinogen, 1, 2-dimethylhydrazine. Biochem Pharmacol 37: 2967-2971, 1988.

118. Burdock GA: Fenaroli's handbook of flavor ingredients: CRC Press, 2016.

119. Smith D, Wang T and Spanel P: On-line, simultaneous quantification of ethanol, some metabolites and water vapour in breath following the ingestion of alcohol. Physiol Meas 23: 477-489, 2002

120. Xu ZQ, Broza YY, Ionsecu R, Tisch U, Ding L, Liu H, Song Q, Pan YY, Xiong FX, Gu KS, et al: A nanomaterial-based breath test for distinguishing gastric cancer from benign gastric conditions. Br J Cancer 108: 941-950, 2013.

121. Eckel RH: Lipoprotein lipase A multifunctional enzyme relevant to common metabolic diseases. New Engl J Med 320 1060-1068, 1989.

122. Jia Z, Zhang H, Ong CN, Patra A, Lu Y, Lim CT and Venkatesan T: Detection of lung cancer: Concomitant volatile organic compounds and metabolomic profiling of six cancer cell lines of different histological origins. ACS Omega 3: 5131-5140, 2018.
123. Peled N, Barash O, Tisch U, Ionescu R, Broza YY, Ilouze M, Mattei J, Bunn PA Jr, Hirsch FR and Haick H: Volatile fingerprints of cancer specific genetic mutations. Nanomedicine 9: 758-766, 2013.

124. Yang B, Zhang H, Shu J, Ma P, Zhang P, Huang J, Li Z and $\mathrm{Xu}$ C: Vacuum-ultraviolet-excited and $\mathrm{CH}_{2} \mathrm{Cl}_{2} / \mathrm{H}_{2} \mathrm{O}$-amplified ionization-coupled mass spectrometry for oxygenated organics analysis. Anal Chem 90: 1301-1308, 2018.

125. Huang J, Yang B, Shu J, Zhang Z, Li Z and Jiang K: Kinetic understanding of the ultrahigh ionization efficiencies (up to $28 \%$ ) of excited-state $\mathrm{CH}_{2} \mathrm{Cl}_{2}$-induced associative ionization: A case study with nitro compounds. Anal Chem 91: 5605-5612, 2019.

This work is licensed under a Creative Commons Attribution-NonCommercial-NoDerivatives 4.0 International (CC BY-NC-ND 4.0) License. 